\title{
Tuning the Magnetic Properties of $\mathrm{MoS}_{2}$ Single Nanolayers by $3 d$ Metals Edge Doping
}

\author{
Mohamad Saab, Pascal Raybaud*
}

IFP Energies nouvelles, Rond-point de l'échangeur de Solaize BP 3, 69360 Solaize, France

Corresponding author: pascal.raybaud@,ifpen.fr, +33.4.37.70.23.20 


\section{S1. Complementary DFT data on magnetic properties of bulk sulfides}

The magnetic properties of three reference bulk monosulfides have been calculated and we found very similar results as the previous data reported by Hobbs and Hafner. ${ }^{2}$ This also confirms the reliability of the methods to evaluate the magnetic properties of our systems. As observed in Ref.

1 , including spin polarized corrections leads to a significant improvement of the structural properties of the bulk monosulfides, with respect to non-spin polarized calculations.

Table S1. Calculated magnetic ordering and magnetic moment of the reference bulk sulfides.

\begin{tabular}{lll}
\hline $\begin{array}{l}\text { Monosulfide } \\
\text { phase }\end{array}$ & $\begin{array}{l}\text { Magnetic } \\
\text { Ordering }\end{array}$ & $\begin{array}{l}\text { Magnetic Moment on Me } \\
\left(\mu_{\mathrm{B}} / \mathrm{Me} \text { atom }\right)\end{array}$ \\
\hline VS (NiAs) & $\mathrm{NM}$ & 0 \\
$\mathrm{CrS}(\mathrm{NiAs})$ & AFM & $2.63(2.55)^{*}$ \\
$\mathrm{MnS}(\mathrm{NaCl})$ & AFM & $4.14(4.08)^{*}$ \\
$\mathrm{MnS}_{2}\left(\mathrm{FeS}_{2}\right)$ & $\mathrm{FM}$ & $1.12(1.16)^{*}$ \\
$\mathrm{FeS}(\mathrm{NiAs})$ & $\mathrm{NM}$ & 0 \\
$\mathrm{CoS}(\mathrm{NiAs})$ & $\mathrm{NM}$ & 0 \\
\hline
\end{tabular}

*values in parenthesis are from Ref. 2

(1) Krebs, E; Silvi, B.; Raybaud, P. J. Catal. 2008, 130, 160-169.

(2) Hobbs, D.; Hafner, J. J. Phys.: Condens. Matter 1999, 11, 8197-8222. 


\section{S2. Structural, magnetic and energetic properties of the $\mathrm{Me}-\mathrm{MoS}_{2}$ edges}

Table S2. Magnetic properties, local structures and energies of the MeMoS M-edge $(\mathrm{Me}=\mathrm{V}$, $\mathrm{Cr}, \mathrm{Mn}, \mathrm{Fe}$ and $\mathrm{Co})$.

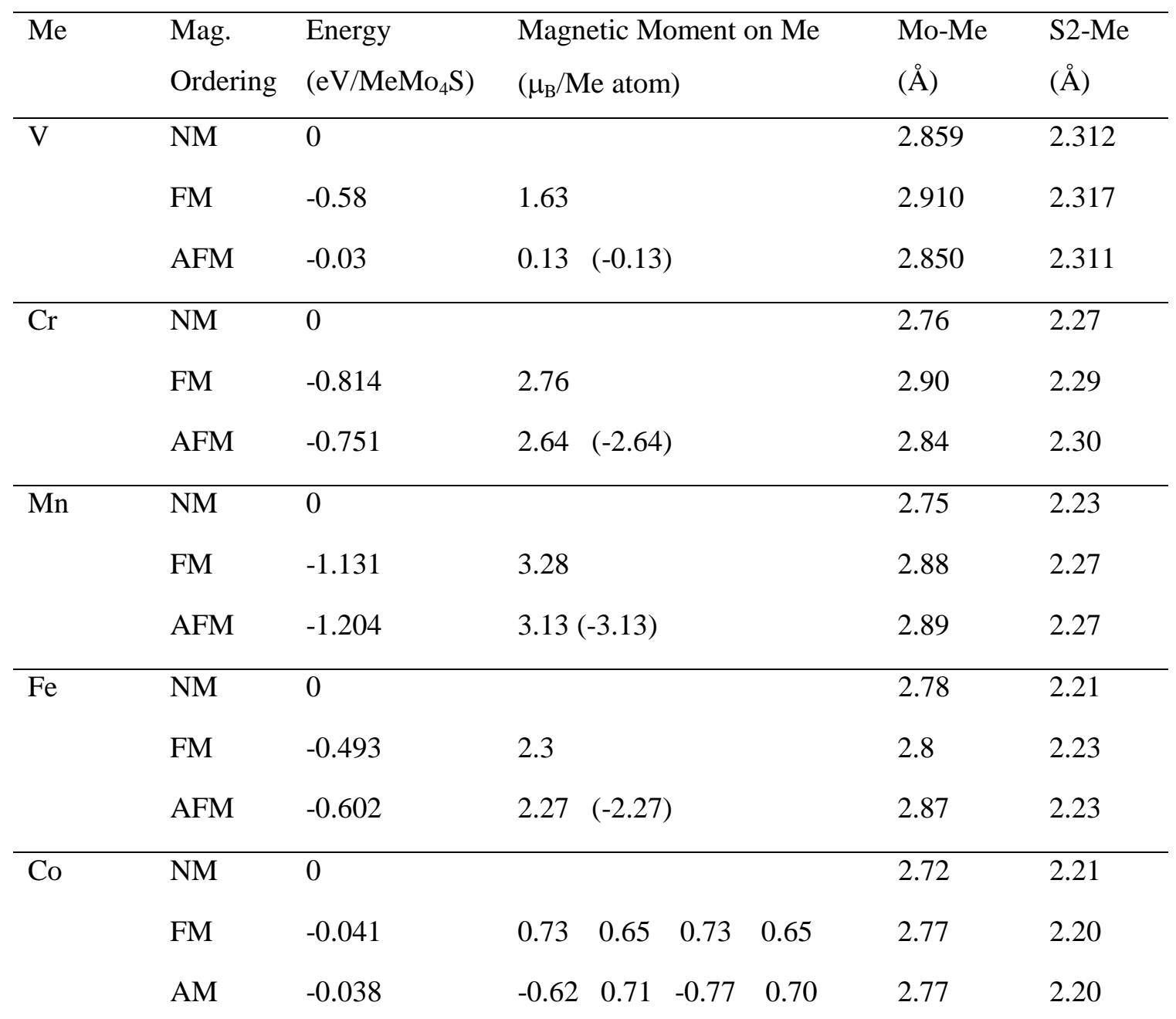

The local distances reported in Table S3 correspond to the structure reported in figure S2, where S1 and S2 atoms correspond to the two types of S-bridging atoms (see also main text). 


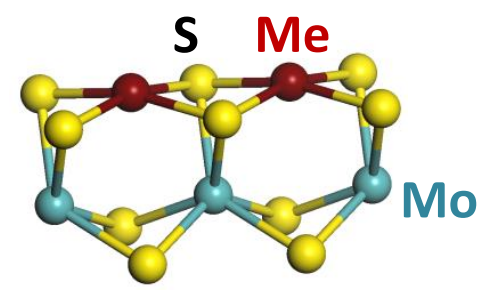

Figure S1. Square planar M-edge structure for MeMoS. Color legend: blue balls: Mo atoms, brown balls: Me atoms, Yellow balls: S atoms (S1 and S2 types). 
Table S3. Magnetic properties, local distances and relative energies of the MeMoS S-edge $(\mathrm{Me}=$ $\mathrm{V}, \mathrm{Cr}, \mathrm{Mn}, \mathrm{Fe}$ and $\mathrm{Co})$.

\begin{tabular}{lllllll}
\hline Me & $\begin{array}{l}\text { Mag. } \\
\text { Ordering }\end{array}$ & $\begin{array}{l}\text { Energy } \\
\left(\mathrm{eV} / \mathrm{MeMo}_{4} \mathrm{~S}\right)\end{array}$ & $\begin{array}{l}\text { Magnetic Moment on Me } \\
\left(\mu_{\mathrm{B}} / \mathrm{Me} \text { atom }\right)\end{array}$ & $\begin{array}{l}\text { Mo-Me } \\
(\AA)\end{array}$ & $\begin{array}{l}\mathrm{S} 2-\mathrm{Me} \\
(\AA)\end{array}$ & $\begin{array}{l}\mathrm{S} 1-\mathrm{Me} \\
(\AA)\end{array}$ \\
\hline $\mathrm{V}$ & $\mathrm{NM}$ & 0 & & 2.985 & 2.206 & 2.220 \\
& FM & -0.050 & 0.33 & 2.830 & 2.213 & 2.200 \\
& AFM & -0.060 & $0.24(-0.20)$ & 2.975 & 2.207 & 2.208 \\
\hline Cr & NM & 0 & & 2.981 & 2.146 & 2.176 \\
& FM & -0.808 & 1.460 & 2.984 & 2.175 & 2.192 \\
& AFM & -0.809 & $1.576(-1.517)$ & 2.944 & 2.184 & 2.197 \\
\hline Mn & NM & 0 & & 2.975 & 2.092 & 2.153 \\
& FM & -1.050 & 2.237 & 2.982 & 2.164 & 2.190 \\
& AFM & -0.999 & $2.019(-1.502)$ & 2.975 & 2.093 & 2.153 \\
\hline Fe & NM & 0 & & 2.919 & 2.050 & 2.140 \\
& FM & 0.003 & 0.152 & 2.924 & 2.061 & 2.140 \\
\hline Co & NM & 0 & & 2.970 & 2.101 & 2.153 \\
\hline
\end{tabular}

The local distances reported in Table S3 corresponds to the edge structure illustrated in Figure S3, where atoms S1 and S2 correspond to the two types of S-bridging atoms (see also main text).

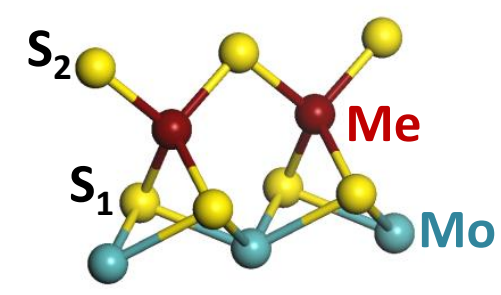

Figure S2. Tetrahedral S-edge structure for MeMoS. Color legend: blue balls: Mo atoms, brown balls: Me atoms, Yellow balls: S atoms (S1 and S2 types). 
S3. Projected Density of States (PDOS) of the non-magnetic edges
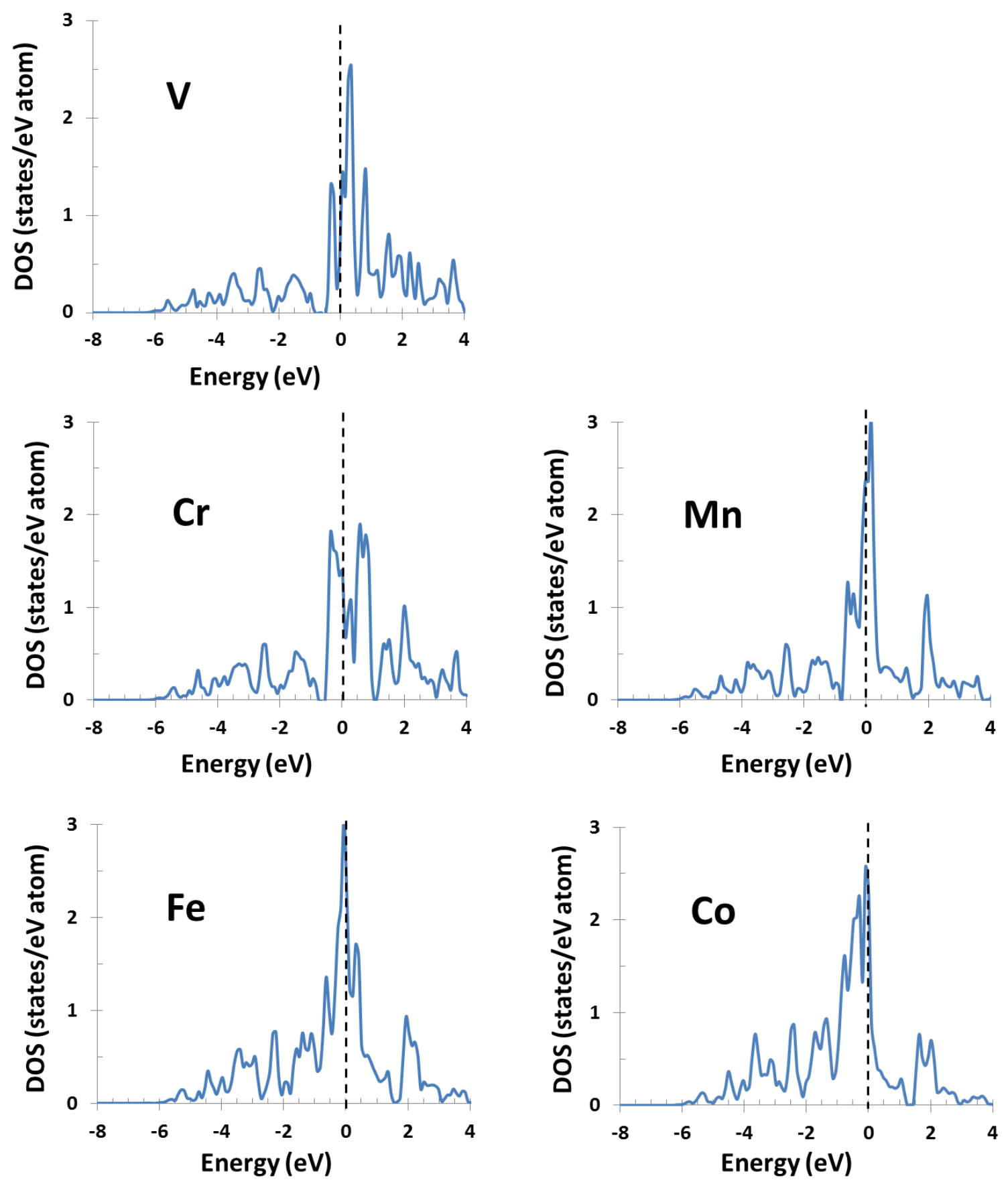

Figure S3. Projected density of states on the dopant Me sites for the non-magnetic M-edge with $\mathrm{Me}=\mathrm{V}, \mathrm{Cr}, \mathrm{Mn}, \mathrm{Fe}, \mathrm{Co}$. 

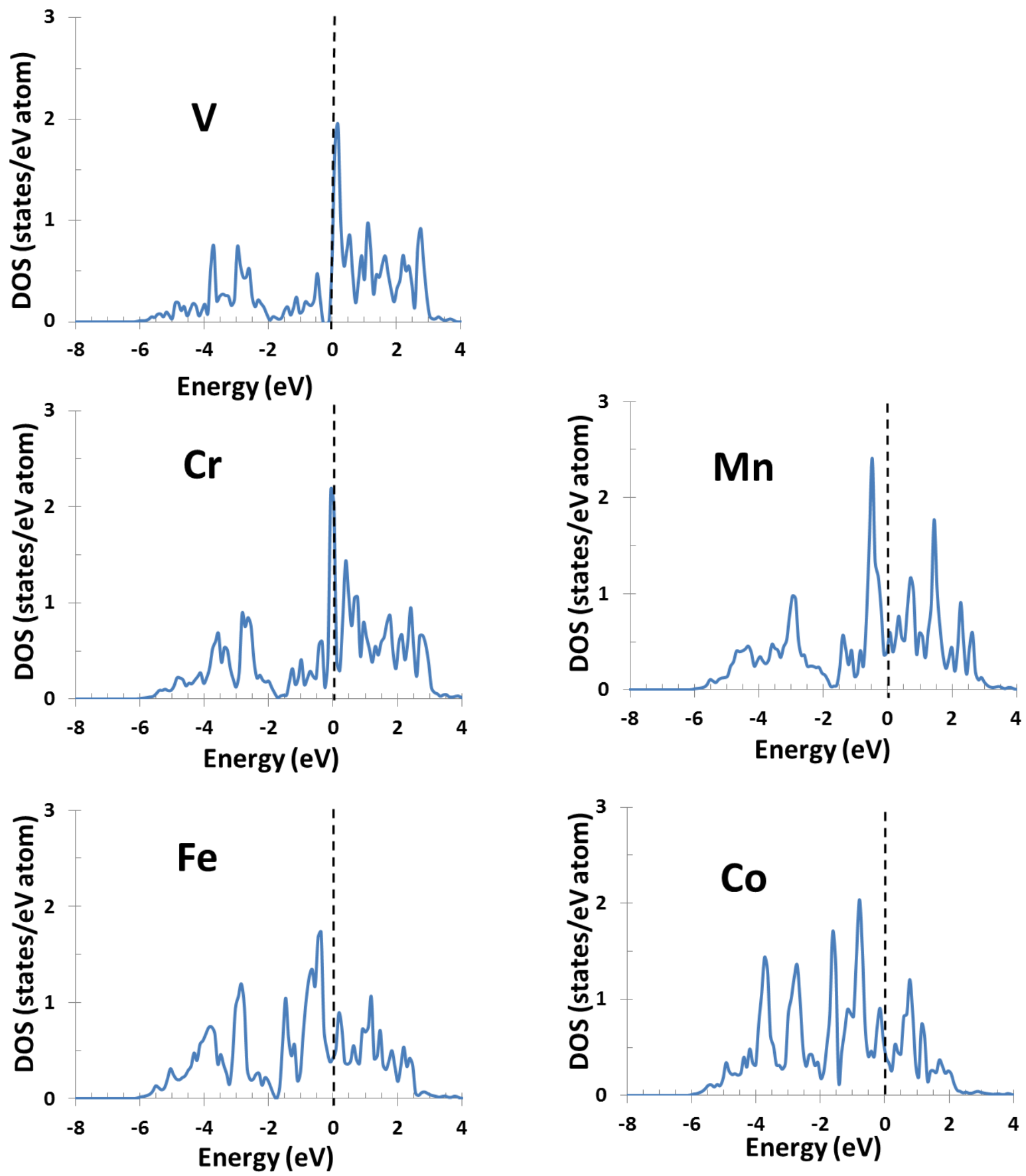

Figure S4. Projected density of states on the dopant Me sites for the non-magnetic M-edge with $\mathrm{Me}=\mathrm{V}, \mathrm{Cr}, \mathrm{Mn}, \mathrm{Fe}, \mathrm{Co}$. 


\section{S4. Projected Density of States (PDOS) of the magnetic edges for Mn-MoS}

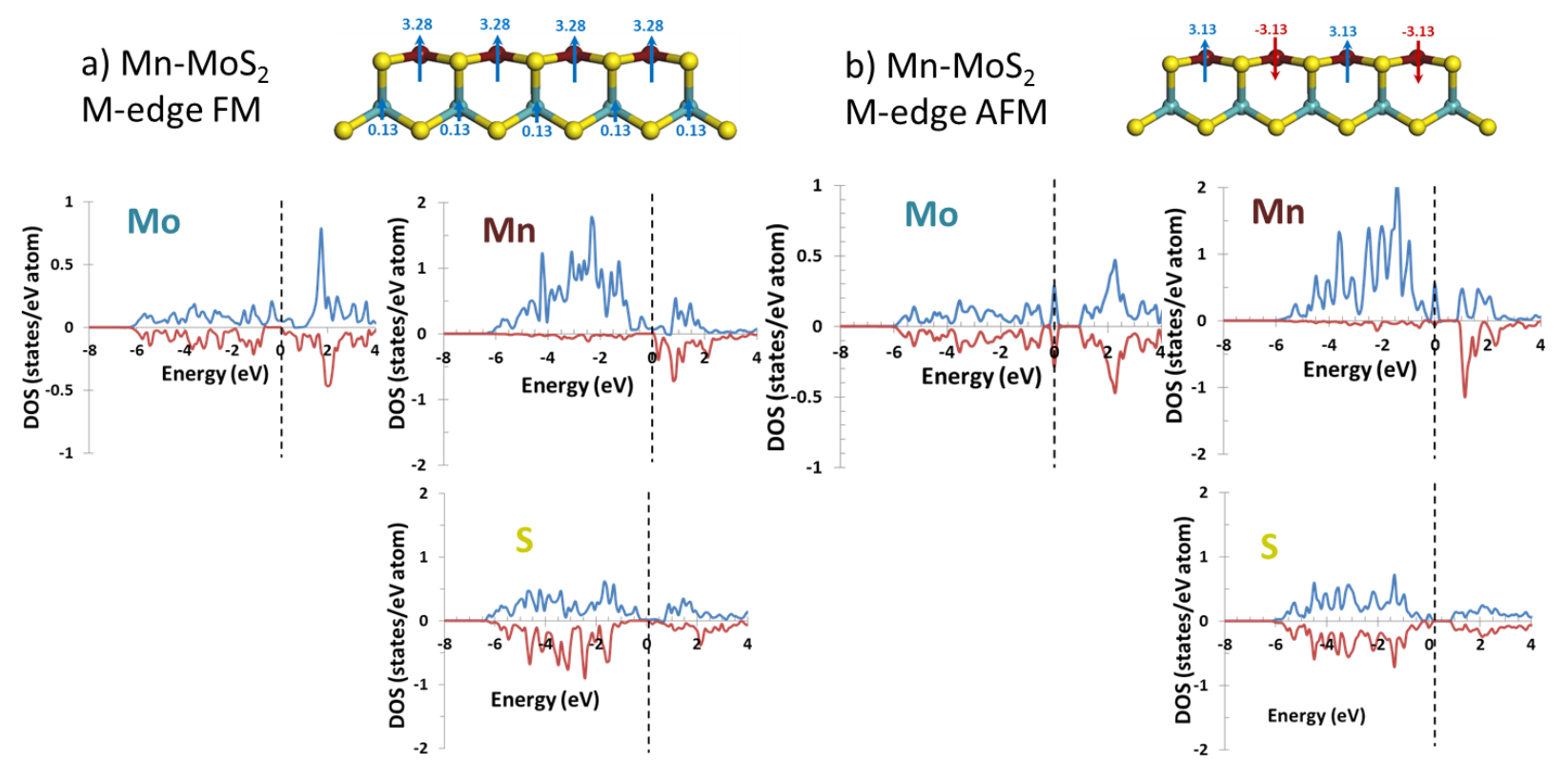

Figure S5. Projected density of states (PDOS) on Mn, Mo and S at the M-edge for the FM (a) and AFM (b) orderings. The local structures (top) illustrate the magnetization of Mn edge atoms associated to the magnetization of Mo sub-edge atoms in the case of FM.

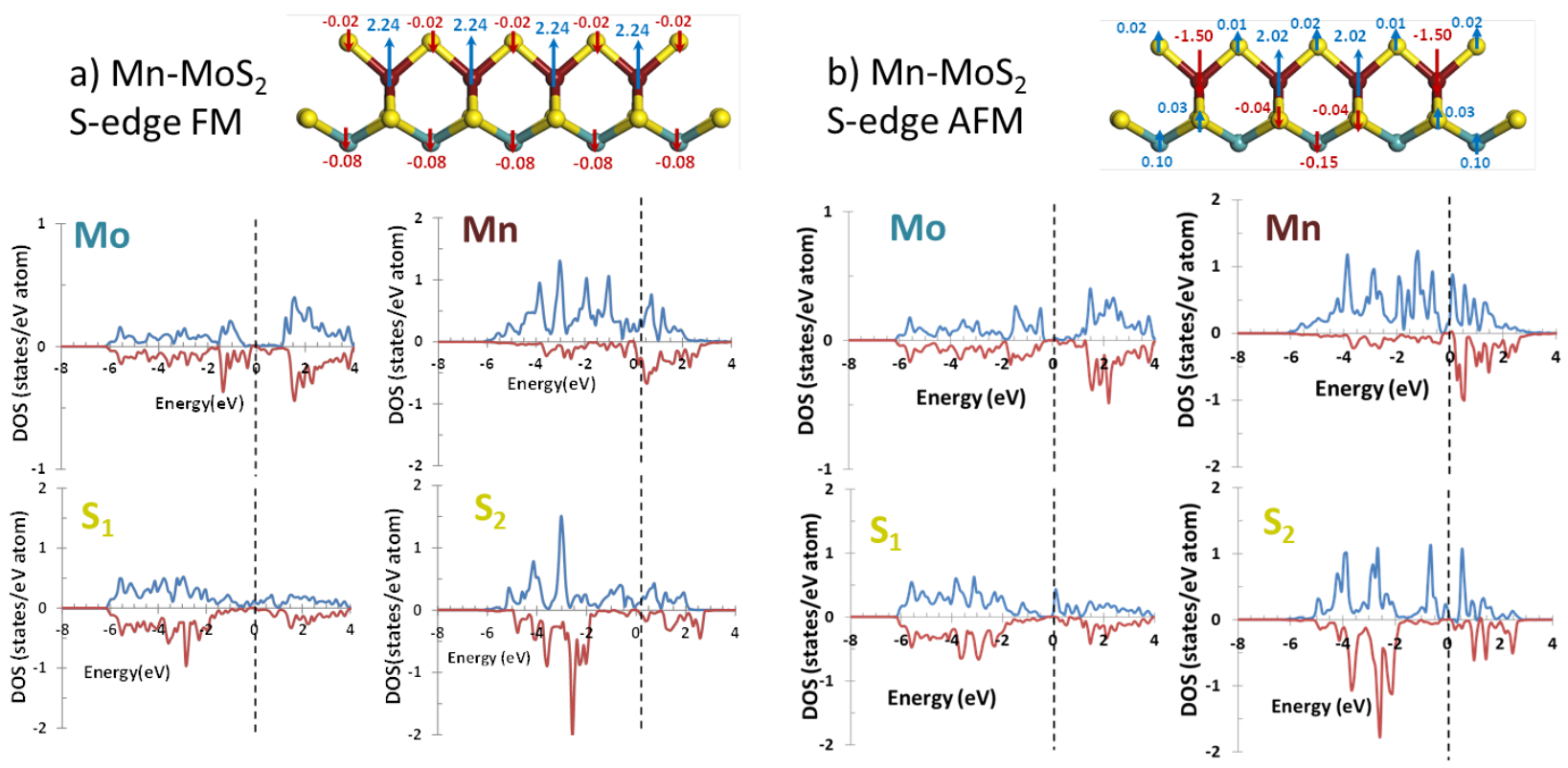

Figure S6. Projected density of states (PDOS) on Mn, Mo and S at the S-edge for the FM (a) and AFM (b) orderings. The local structures (top) illustrate the magnetization of Mn edge atoms associated to the magnetization of Mo sub-edge atoms and S bridging atoms in the case of AFM. 